ted during each peer review period. However, because our sample consisted of large numbers of abstracts examined over a short study period, quality variations within categories of submitted abstracts during each peer review period are likely to be negligible. Therefore, for variation in abstract quality to explain our findings, there would need to be meaningful variations in the proportion of submitted abstracts among categories during each peer review period.

We examined this issue and determined that the proportion of submitted abstracts accepted and the proportions of submitted abstracts categorized by the author's sex, country, country's language, institution's prestige, and institution's status as government or industry were all consistent over our 5 -year study period. We also determined that there was little change among reviewers during our study period. The strongest and most likely explanation for our findings was the presence of reviewer bias affecting the acceptance of abstracts evaluated using open peer review, a bias that was at least partially reduced after implementation of blinded peer review.

We disagree with Dr Falagas that knowing the identity of the authors and their institutions (so that consideration can be given to various factors, such as the quality record of previous publications) would benefit the peer review of research abstracts. Research should be evaluated solely on its scientific merit and quality. No matter an author's or institution's past successes or failures, the merit and quality of the current research must be made clear to any reviewer, since the purpose of scientific conferences is to advance the current understanding of disease and therapy.

We do agree that information regarding sponsorship and research funding should be included with the research abstract for peer review, although without inclusion of the author's name and institution. Since industry-funded research is more likely to report positive findings ${ }^{1}$ and to favor the industry product, ${ }^{2}$ providing sponsorship information may allow peer reviewers to make more informed evaluations.

Joseph S. Ross, MD

Harlan M. Krumholz, MD, SM

harlan.krumholz@yale.edu

Department of Internal Medicine

Yale University School of Medicine

New Haven, Conn

Financial Disclosures: None reported

1. Ridker PM, Torres J. Reported outcomes in major cardiovascular clinical trials funded by for-profit and not-for-profit organizations: 2000-2005. JAMA. 2006;295 2270-2274.

2. Bhandari $M$, Busse JW, Jackowski D, et al. Association between industry funding and statistically significant pro-industry findings in medical and surgical randomized trials. CMAJ. 2004;170:477-480.

\section{Effects of Differences Between Peer Reviewers Suggested by Authors and by Editors}

To the Editor: Dr Schroter and colleagues ${ }^{1}$ reported that a recommendation of manuscript acceptance (vs revision or rejection) was more common from reviewers suggested by authors compared with reviewers selected by editors (odds ratio [OR], 1.6). Furthermore, author-suggested reviewers more often recommended acceptance or revision (vs rejection) compared with editor-selected reviewers (OR, 2.7).

These ORs were estimated using conditional logistic regression, thereby comparing recommendations regarding the same manuscript. Acceptance was the recommendation for $51 \%$ of the study manuscripts and acceptance or revision was recommended for $81 \%$. These ORs (and the OR of 12.4 in Table 2 of the study) cannot be easily interpreted, as ORs are further from 1 than risk ratios (RRs) when the outcome is common. ${ }^{2,3}$ In this case, the respective RRs cannot be estimated from the published data. It would enhance the usefulness of the study if Schroter et al could also estimate and report RRs conditional on each manuscript. This could be done using either conditional Poisson regression or stratified Cox proportional hazards regression; both methods are available with the software the authors used. ${ }^{4,5}$ In these data, the usual confidence intervals from these regression methods will be too wide but this can be remedied by using bootstrap methods.

Peter Cummings, MD, MPH

peterc@u.washington.edu

Department of Epidemiology

Harborview Injury Prevention and Research Center

University of Washington

Seattle

Financial Disclosures: None reported.

1. Schroter $S$, Tite $L$, Hutchings $A$, Black N. Differences in review quality and recommendations for publication between peer reviewers suggested by authors or by editors. JAMA. 2006;295:314-317.

2. Altman DG, Deeks JJ, Sackett DL. Odds ratios should be avoided when events are common. BMJ. 1998;317:1318.

3. Schwartz LM, Woloshin S, Welch HG. Misunderstanding about the effects of race and sex on physicians' referrals for cardiac catheterization. N Engl J Med. 1999; 341:279-283.

4. Cummings $P$, McKnight $B$, Greenland $S$. Matched cohort methods in injury research. Epidemiol Rev. 2003;25:43-50.

5. Cummings P, McKnight B. Analysis of matched cohort data. Stat J. 2004;4:274281.

In Reply: We agree with Dr Cummings' analysis that ORs are not a good approximation to RRs when the risk of the outcome is large. The TABLE shows the original ORs with RRs for the same outcomes. Risk ratios were estimated by conditional Poisson regression with bootstrapped 95\% confidence intervals (2000 replications sampling by study). ${ }^{1,2}$ We also report the RR for the alternative outcome (eg, reject vs accept or revise) because it is not the reciprocal of the original RR. The OR of the alternative outcome is the reciprocal of the OR of the original outcome.

It is important to interpret the effects of matched studies correctly, and in our study, all measures of effect are potentially useful. Risk ratios measure differences between reviewers' recommendations for all papers reviewed. Odds ratios measure differences between reviewers' recommendations for those papers in which the reviewers provided different recommen-

(Reprinted) JAMA, September 13, 2006-Vol 296, No. $10 \mathbf{1 2 3 1}$ 
Table. Relative Odds and Risk Ratios for Recommendations by Author-Suggested Reviewers Compared With Editor-Suggested Reviewers

\begin{tabular}{|c|c|c|c|c|c|c|}
\hline & \multicolumn{2}{|c|}{ Accept (vs Revise or Reject) } & $\begin{array}{l}\text { Revise or Reject } \\
\text { (vs Accept) }\end{array}$ & \multicolumn{2}{|c|}{$\begin{array}{l}\text { Accept or Revise } \\
\text { (vs Reject) }\end{array}$} & $\begin{array}{c}\text { Reject } \\
\text { (vs Accept or Revise) }\end{array}$ \\
\hline & $\begin{array}{l}\text { Odds Ratio } \\
(95 \% \mathrm{Cl})\end{array}$ & $\begin{array}{l}\text { Risk Ratio } \\
(95 \% \mathrm{Cl})\end{array}$ & $\begin{array}{l}\text { Risk Ratio } \\
(95 \% \mathrm{Cl})\end{array}$ & $\begin{array}{l}\text { Odds ratio } \\
(95 \% \mathrm{Cl})\end{array}$ & $\begin{array}{l}\text { Risk ratio } \\
(95 \% \mathrm{Cl})\end{array}$ & $\begin{array}{l}\text { Risk ratio } \\
(95 \% \mathrm{Cl})\end{array}$ \\
\hline Papers with blinded reviews & $1.64(1.02-2.66)$ & $1.21(1.01-1.45)$ & $0.81(0.66-0.996)$ & $2.66(1.43-4.97)$ & $1.18(1.06-1.30)$ & $0.51(0.33-0.79)$ \\
\hline Papers with open reviews (BMJ) & $12.4(1.60-95.8)$ & $2.59(1.25-5.39)$ & $0.52(0.34-0.80)$ & & & \\
\hline
\end{tabular}

Abbreviation: $\mathrm{Cl}$, confidence interval.

dations. In this situation, editors are arguably most interested in knowing who is providing the more (or less) favorable recommendations.

Sara Schroter, PhD
sschroter@bmj.com
Leanne Tite, MSc
BMJ Editorial Office
BMA House
London, England
Andrew Hutchings, MSc
Nick Black, MD
Health Services Research Unit
London School of Hygiene and Tropical Medicine
London, England

Financial Disclosures: None reported.

1. Cummings $P$, McKnight $B$, Greenland $S$. Matched cohort methods for injury research. Epidemiol Rev. 2003;25:43-50.

2. Cummings $P$, McKnight B. Analysis of matched cohort data. Stat J. 2004;4:274281.

\section{Remission of Maternal Depression and Children's Psychopathology}

To the Editor: The article by Dr Weissman and colleagues ${ }^{1}$ demonstrated that remission of maternal depression after treatment was correlated with reduction in children's psychiatric diagnoses and treatment. The authors plausibly conclude that this suggests an effect of the maternal disorder on the child, but in their "Comment" section, they recognize that they have not demonstrated causality and that reverse causality or an unknown common cause are also possible. They give as an example a contemporary environmental event, reduction in levels of stress.

Another possibility could be a prior common cause. Failure to improve with treatment would then be a marker for severity in the mother that is also reflected in increased severity in the child, because of either genetic or earlier environmental causes. The mother's improvement would not be a cause of the child's improvement but rather a predictor of the child also having a less severe course. Although this seems less plausible than their suggested interpretation, it is not logically excluded by their data.

Robert Michels, MD

Department of Psychiatry

rmichels@med.cornell.edu

Weill Medical College of Cornell University

New York, NY

1232

JAMA, September 13, 2006-Vol 296, No. 10 (Reprinted)
Financial Disclosures: None reported.

1. Weissman MM, Pilowsky DJ, Wickramaratne PJ, et al; STAR*D-Child Team Remissions in maternal depression and child psychopathology: a STAR*D-Child report. JAMA. 2006;295:1389-1398.

To the Editor: Dr Weissman and colleagues ${ }^{1}$ reported that remission of maternal depression after 3 months of pharmacological treatment was associated with an overall $11 \%$ decrease in the rate of diagnoses in their children, whereas nonremission was associated with an $8 \%$ increase in the rate of diagnoses after this period. Mothers and children were interviewed through the Kiddie Schedule for Affective Disorders and Schizophrenia for School-age Children-Present and Lifetime Version (K-SADS-PL) to establish categorical diagnosis, and mothers completed the Child Behavior Checklist.

It was ambiguous how diagnoses were established through the K-SADS-PL because there are several strategies to assign a diagnosis when interviewing 2 informants. A diagnosis may be considered positive if symptoms are endorsed by both informants ("and" rule), or if symptoms are endorsed by either of them ("or" rule). In addition, interviewers can collect information from both sources and establish a diagnosis based on a clinical decision (best estimate). This is relevant to the purpose of this study because the rate of diagnoses may vary according to the strategy applied.

Depressed mothers overreport symptoms of their children, ${ }^{2,3}$ which may have occurred in this study. Once the remission of maternal symptoms occurred, mothers could have perceived their children in a more realistic way, attenuating the previous overreport. The instructions in the mood disorders section of the K-SADS-PL ${ }^{4}$ actually emphasize that a maternal subjective impression that her child feels depressed is evidence of the child's depression, except if the mother is concurrently depressed. The reduction of children's rate of disorders when there was a remission of mother's depression after such a short period noted in Weissman et al could be related to a biased report of symptoms.

The authors reported that there were no clinically or statistically significant differences between maternal and child reports of depressive and anxiety symptoms. Nevertheless, the main outcome was the rate of diagnoses, not the rate of symptoms. The results reported would have been strengthened if there were data from independent sources (such as

(02006 American Medical Association. All rights reserved. 